\title{
Experimental approach to rootless eruptions using kitchen materials
}

\author{
Rina Noguchi ${ }^{1} 2^{*} \mathbb{D}$, Ai Hamada ${ }^{3}$, Ayako I. Suzuki ${ }^{2}$ and Kei Kurita ${ }^{4}$
}

\begin{abstract}
Rootless eruption is caused by lava flow entering inland water or wet sediment and forms craters and cones far from the actual vent. Since the rootless eruption can be significantly explosive, the possibility of rootless eruption is critical for hazard management; however, forecasting occurrence and explosiveness of a rootless eruption remains difficult because explosiveness is considered to correlate nonlinearly with the mass ratio of hot lava and water. Here, we show the nonlinear nature of this type of eruption roots from the nonlinearly determined area between lava and underlying wet sediment as a function of water content within the wet sediment by a series of analog experiments can be implemented in a kitchen. In our analog experiment, lava and wet sediment were replaced by heated syrup and mixture of baking soda (sodium bicarbonate) and cake syrup. From measurements of mass loss due to $\mathrm{CO}_{2}$ gas emission during the heat-induced decomposition of baking soda, we estimated the reaction efficiency for various proportions of baking soda and cake syrup in the substrate. We observed a nonlinear dependence of $\mathrm{CO}_{2}$ emission; the peak efficiency was achieved for the substrate with 15 and $35 \mathrm{~g}$ of baking soda and cake syrup, respectively. Considering physical properties such as density and viscosity, we found that the Rayleigh-Taylor instability between the poured heated syrup and the substrate can explain the observed nonlinear dependence of $\mathrm{CO}_{2}$ emission. For natural settings, the results of this study suggest that both the availability of water and rheological properties of the substrate affect the occurrence and stability of hydrovolcanic eruptions.
\end{abstract}

Keywords: Rootless eruption, Lava-water interaction, Kitchen earth experiment, Syrup, Soda

\section{Introduction}

Explosions caused by magma making contact with water, such as phreatomagmatic eruptions, vary in their intensity (efficiency of the transformation from thermal to mechanical energy). This variation is considered to correlate with the mass ratio of magma and water (Wohletz and Sheridan 1983), especially for basaltic magma. In water-rich environments, such as submarine regions, for basaltic magma, no vigorous explosion occurs and extruded lava solidifies as pillow lava, sheet-flow lava (e.g., at the ocean entry and on the deep ocean floor), or both, although many exceptions exist. These exceptions may be related to the eruption system (e.g., submarine eruption of Teishi Knoll in 1989; Yamamoto et al. 1991)

\footnotetext{
*Correspondence: r-noguchi@ksvo.titech.ac.jp;

r-noguchi@planeta.sci.isas.jaxa.jp

${ }^{2}$ Present Address: Institute of Space and Astronautical Science, Japan

Aerospace Exploration Agency, Tokyo, Japan

Full list of author information is available at the end of the article
}

and may result from a volatile-rich magma composition. In contrast, in drier environments (far from water sources), lava fragments are ejected ballistically (i.e., Strombolian-style eruption). In a setting with a watermagma mass ratio of around 0.3 (Wohletz and Sheridan 1983, see the supplementary material for details), vigorous eruption occurs and pyroclastic surges are produced (i.e., Surtseyan-, Hawaiian-, and Vulcanian-style eruptions). This explosive interaction of basaltic magma and water has been observed in a subaerial environment (e.g., Ukinrek maars; Kienle et al. 1980). This nonlinear relationship of the explosion intensity in hydrovolcanism has been experimentally investigated (e.g., Zimanowski et al. 1997) with lava-water interaction where there is no direct magma feeding system beneath a volcano (i.e., rootless eruptions; Fagents and Thordarson 2007).

Rootless eruptions are continuous explosive interactions between lava and water-saturated sediments (e.g., Thorarinsson 1953; Mattox and Mangan 1997; Greeley 
and Fagents 2001; Fagents and Thordarson 2007; Hamilton et al. 2010a). When hot molten lava covers watersaturated sediments, explosions occur due to rapid vaporization of packed water by heating. With repeated explosions (i.e., eruptions) and ejection of fragments, caused by subsequent lava flow, a conical body forms, called a rootless cone or pseudocrater. In general, rootless cones have a relatively small edifice ( 5 to $450 \mathrm{~m}$, Fagents and Thordarson 2007, and references therein) compared to that of other volcanoes. Geomorphological and rock sample analyses have shown explosion intensity variation in rootless eruptions (Fagents and Thordarson 2007; Gregg and Christle 2013; Noguchi et al. 2016; Hamilton et al. 2017; Fitch et al. 2017). In the early phase, the eruption is intense enough to produce dilute pyroclastic density currents (Hamilton et al. 2017). Deposits from this phase include not only lava fragments but also aggregates of water-logged sediments ( $\sim 60 \%$ by weight), which is evidence of the dynamic mixing of lava and the waterlogged substrates. Then, through a rhythmic explosion cycle, a conical edifice forms around the explosion center due to the emplacement of a series of lapilli-dominated bed pairs. A lapilli-dominated bed pair consists of a fine lower layer and a coarse upper layer, which are thought to be formed by tephra falling and ballistic ejection, respectively (Hamilton et al. 2017). This rhythmic explosion cycle has been inferred to be the result of a recharge of groundwater to the explosion point (Hamilton et al. 2017). As the eruption proceeds, because available water runs out, the explosion intensity decreases and the ejecta shifts to spatter-dominant (Fagents and Thordarson 2007). Gregg and Christle (2013) showed a non-explosive interaction of lava and water, where only remnants of the steam vent were found as vertical basaltic pipes (lava pillars) in the collapsed area of the lava drainage system because low fragmentation occurred in the interaction. Thus, the interaction of molten lava and water-saturated sediments leads to a wide range of explosion intensities, and there is a nonlinear relationship between explosion intensity and available water. This nonlinear variation in explosion intensity of rootless eruptions is comparable to that of hydrovolcanism (e.g., the Strombolian/HawaiianSurtseyan-submarine sequence) (Wohletz and Sheridan 1983; Fagents and Thordarson 2007). Clarifying explosion processes in rootless eruptions as one of the phenomena of magma and water interaction plays an important role in understanding phreatic and phreatomagmatic eruptions, in which external water drives explosions.

Rootless eruptions have been observed in several environmental settings, but direct documentation is rare due to their short formation timescale. In Hawaii, littoral explosion activities (i.e., lava-sea water interactions) were observed in the period 1992-1994 (Mattox and Mangan 1997). The explosions occurred in a lava tube system on a lava delta, not in a fissure vent system. The explosions were unusual. The longest duration was $43 \mathrm{~h}$, and bubble bursts, lava fountains, steam jets, lithic blasts, and tephra jets were observed. Mattox and Mangan (1997) noted that the trigger of the littoral eruptions was the collapse of a bench (bounded inland by an oceanfacing scarp). Explosive interactions of lava and snow were observed in Fimmvörðuháls during the 2010 Eyjafjallajökull eruption (Thorkelsson et al. 2012). According to Thorkelsson et al. (2012), explosive interactions of lava and snow (water after melting) were observed on several days from the end of March to early April, 2010. The explosions occurred where lava flowed into gullies, not at the fissure vent. As a result of these explosions, small tephra cones (i.e., rootless cones) formed, though they later disappeared due to the coverage by subsequent lava flow (Á. Höskuldsson, personal communication). Although rootless eruptions have been documented, there are no descriptions of a continuous rootless eruption that formed conical edifices.

The triggering and stability of continuous explosions have been the critical argument for a rootless eruption. For rootless eruptions in a littoral area, the collapse of a lava delta and the subsequent inflow of lava into waterbearing coastal sediments triggers lava-water interaction (Mattox and Mangan 1997). For an inland setting, Reynolds et al. (2015) showed a possible stabilizing mechanism of a conduit that can produce continuous rootless eruption. The spatter lining on the inner wall may maintain the conduit during the explosions. There are no integrated explanations of the triggering and continuous maintenance of eruptions that form rootless cones. Rootless eruptions can be hazardous. On March 16, 2017, the explosive interaction of lava and snow on the flank of Mt. Etna injured 10 people, with ejected products ranging from ash to decimeter-sized bombs (Todesco 2017; Andronico et al. 2018). A sudden explosion at the ocean entry of Kilauea, Hawaii, on July 16, 2018, damaged a tour boat, and 23 people were burned by a lava bomb that had penetrated the roof (U.S. Geological Survey 2018; DLNR 2018). In this background, understanding the triggering and stability of continuous explosions in a rootless eruption would contribute to regional disaster prevention around volcanic areas. Furthermore, such an understanding would apply to not only rootless eruptions but also other external water-related volcanic eruptions.

In this study, we conducted experiments of rootless eruptions to verify the nonlinear relationship of their explosion intensity. We used heated syrup as an analog of high-temperature lava and a mixture of baking soda (sodium bicarbonate) and cake syrup as that of water-saturated sediments. In this experimental setting, bubbling 
of substrate water was simulated by decomposition of the baking soda, although the bubbling observed in our experiment was not explosive and caused no ejection of material. This study thus focuses on the efficiency of the reaction in terms of the magnitude of thermal decomposition of the baking soda by poured heated syrup. For the analog rootless eruptions, we attempt to determine the trigger of explosions and explain explosion stability. This experiment is the first to create analog rootless eruptions using kitchen materials.

\section{Experimental method}

The basic procedure for our experiment is similar to that in a karumeyaki (Japanese honeycomb toffee) recipe (Additional file 1: Fig. S1). As an analog for water vaporization, which drives rootless eruptions in nature, we use $\mathrm{CO}_{2}$ emission from the thermal decomposition of baking soda (sodium bicarbonate). Sodium bicarbonate $\left(\mathrm{NaHCO}_{3}\right)$ thermally decomposes into sodium carbonate $\left(\mathrm{Na}_{2} \mathrm{CO}_{3}\right)$, water $\left(\mathrm{H}_{2} \mathrm{O}\right)$, and carbon dioxide $\left(\mathrm{CO}_{2}\right)$.

$$
2 \mathrm{NaHCO}_{3} \longrightarrow \mathrm{Na}_{2} \mathrm{CO}_{3}+\mathrm{H}_{2} \mathrm{O}+\mathrm{CO}_{2} \uparrow
$$

Because of this reaction, sodium bicarbonate is often used as a leavening agent in cooking. We used heated syrup (Kogo Starch Co. Ltd) as an analog of molten lava, and baking soda (Shouwa Seiyaku) and cake syrup (TOPVALU) as that of the substrate (Additional file 1: Fig. S2). The substrate, prepared to be $50 \mathrm{~g}$ in total, was poured into a petri dish (inner diameter: $76 \mathrm{~mm}$ ). First, we heated the syrup to around $140^{\circ} \mathrm{C}$ using an induction cooktop. After heating, the syrup was kept still for about $20 \mathrm{~s}$ to remove the bubbles generated during heating. We poured the heated syrup onto substrates with various ratios of baking soda and cake syrup, covering their surface completely (roughly $40 \mathrm{~g}$ of syrup per substrate). Since the density of the heated syrup is higher than that of the substrate, the poured syrup sank in the substrate. The heat of the syrup induced the thermal decomposition of the substrate. During the experiment, we logged the mass changes due to $\mathrm{CO}_{2}$ emission using an electric balance (EK-610i, A\&D Company). To quantify reaction efficiency, the decomposed percentage of baking soda ( $\left.D_{\text {soda }}\right)$ was calculated as follows:

$$
D_{\text {soda }}=\frac{\left(\mathrm{mol}_{\mathrm{CO}_{2}} \times 84 \times 2\right)}{S}
$$

where $\mathrm{mol}_{\mathrm{CO}_{2}}$ is the amount (mol) of produced $\mathrm{CO}_{2}$, and 84 and 2 come from the molecular weight of $\mathrm{NaHCO}_{3}$ and the amount (mol) of decomposed $\mathrm{NaHCO}_{3}$, respectively. $S$ is the input weight of baking soda. After the experiment, we measured the size of bubbles generated on the surface of the solidified syrup using ImageJ software (version 1.49). We visually identified bubbles and approximated them as ellipses. The bubble size, bubble area, and their totals were calculated using the "Analyze Particles" function after binarization to select bubble areas.

\section{Results}

In the experiments, we found a peak in the final mass loss for the substrate with $15 \mathrm{~g}$ of baking soda and 35 $\mathrm{g}$ of cake syrup (Fig. 1b). Hereafter, the proportion of baking soda and syrup is shown (e.g., 15-35 substrate). Figure 1a shows the mass change of the system during experiments. The mass rapidly decreased in the first $100 \mathrm{~s}$ for $5-45,10-40,15-35,20-30$, and $25-25$ substrates. We observed small mass loss $(0.31 \mathrm{~g})$ for the $0-50$ substrate. We regarded this mass change as being due to the generation and release of water vapor by an interaction of poured heated syrup and the water in the cake syrup. Assuming this, we obtained an efficiency of $0.31 / 50=0.0062 \mathrm{~g}$ per gram of poured syrup. Considering this effect, we calculated mass loss caused by baking soda decomposition (i.e., generation and release of $\mathrm{CO}_{2}$ ). In our experimental setting, the maximum mass loss was observed for the 15-35 substrate ( $0.83 \mathrm{~g}$, Additional file 1: Table S1). This nonlinear peak seems enigmatic because of the occurrence of increasing amount of the source material in more soda-rich substrates. For the 15-35 substrate, rapid mass loss was initially observed (Fig. 1a). The decomposed baking soda ratio (decomposed baking soda mass calculated from generated $\mathrm{CO}_{2}$ /input baking soda mass) is high at low baking soda content and low at high baking soda content (Fig. 1c).

The surface of the solidified heated syrup is characterized by a vesiculated structure (Fig. 2, Additional file 1: Figs. S3-S11). The circular structures are quenched remnants of $\mathrm{CO}_{2}$ bubbles on the surface. The bubble size, total number of bubbles, and bubble number density greatly vary with substrate composition (Fig. 1d, e). Bubble number density is relatively high for $5-45,10-40$, and 15-35 substrates. Bubble occupancy (bubble area/ area of petri dish) is relatively high for 15-35, 20-30, and 25-25 substrates. We found four patterns for the bubble characteristics: (1) Only a few microbubbles $\left(<1 \mathrm{~mm}^{2}\right)$ were observed for the 0-50 substrate, (2) small bubbles $\left(1 \sim 10 \mathrm{~mm}^{2}\right)$ were dominant for the $5-45,10-40$, and 15-35 substrates, (3) large bubbles $\left(10 \sim 1000 \mathrm{~mm}^{2}\right)$ with much smaller bubbles $\left(1 \sim 10 \mathrm{~mm}^{2}\right)$ within them were dominant for the $20-30,25-25,30-20$, and 35-15 substrates, and (4) one large bubble was observed for the 50-0 substrate. Figure 3 shows a photograph of a petri dish taken from below the dish in an experiment with the 15-35 substrate. When the substrate was washed out with tap water, many holes connected to the internal void 

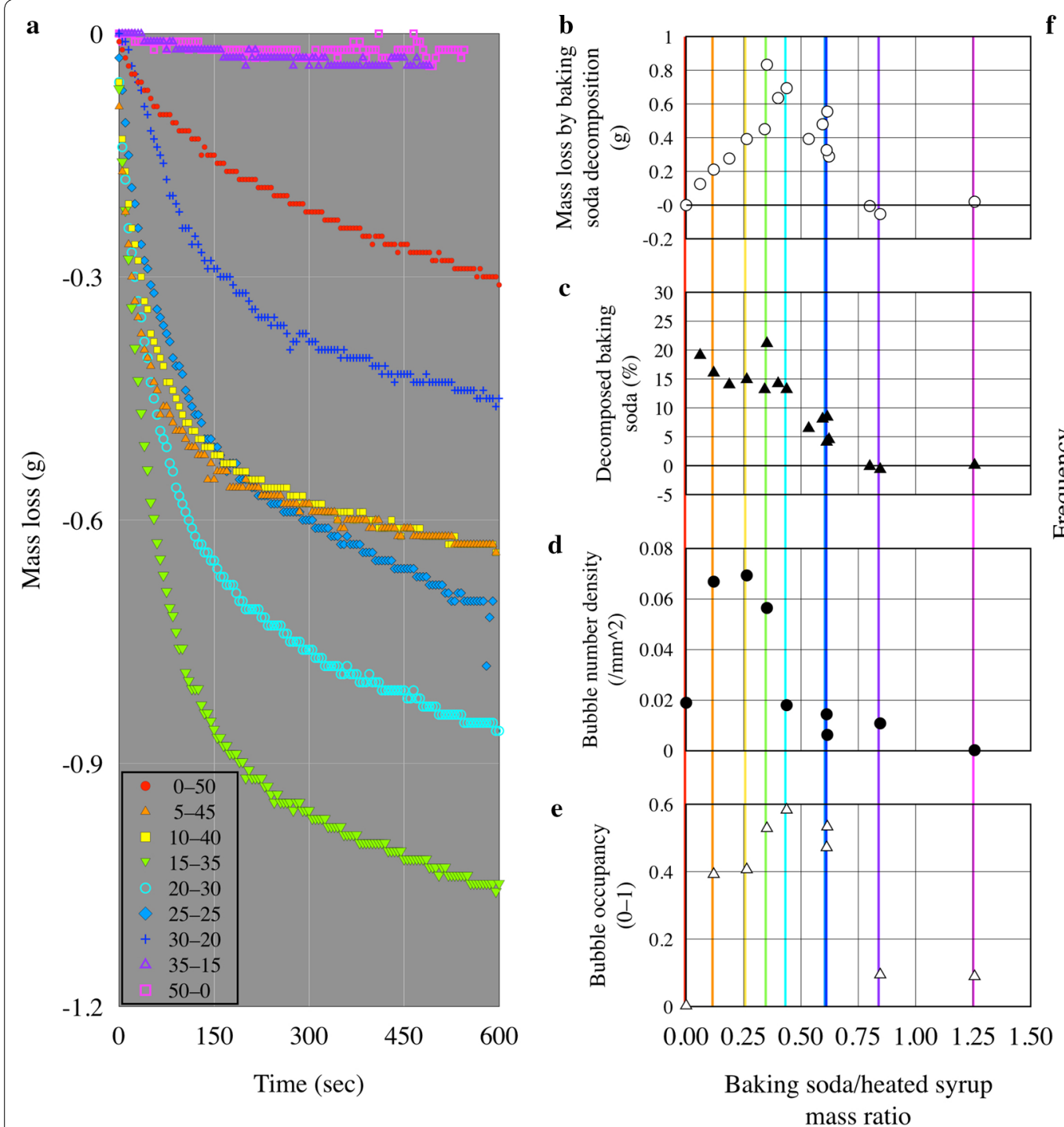

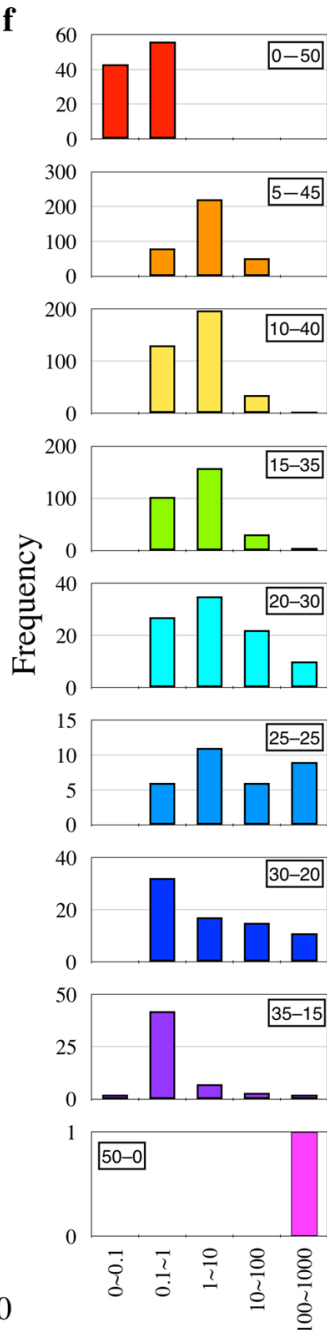

Bubble area $\left(\mathrm{mm}^{2}\right)$

Fig. 1 Experimental results. a Mass changes of the system during experiments. Relationship between the mass ratio of baking soda/poured heated syrup and $\mathbf{b}$ mass losses caused by baking soda decomposition, $\mathbf{c}$ percentage of decomposed baking soda, $\mathbf{d}$ bubble number density, and $\mathbf{e}$ bubble occupancy in a petri dish. $\mathbf{f}$ Bubble size and number for each substrate composition. Colors correspond to substrate composition, as shown in the legend in $\mathbf{a}$. $\mathbf{S}=$ mass of baking soda $(\mathrm{g}), \mathbf{C}=$ mass of cake syrup $(\mathrm{g})$

space were found. They are vents through which $\mathrm{CO}_{2}$ gas continuously escaped.

The load and flame structure of the heated syrup and the substrate after the experiment (e.g., Fig. 3) suggests that the heated syrup sank into the substrate during the experiments. Such a load and flame structure of a viscous fluid is associated with Rayleigh-Taylor instability (RTI). RTI refers to the instability of the interface between two fluids with different densities, which occurs when a heavy fluid superposes a lighter fluid in a gravitational field (Rayleigh 1882; Taylor 1950). The density of the heated syrup (upper layer) was higher than that of the substrate in the experiments with 0 to $15 \mathrm{~g}$ baking soda content $\left(1.47 \mathrm{~g} / \mathrm{cm}^{3}\right.$ for the heated syrup, 1.35 to $1.44 \mathrm{~g} / \mathrm{cm}^{3}$ for the substrate, as shown in Additional file 1: Table S2). In addition, extra experiments (Additional file 1: Figs. S12, S13) confirmed that RTI could occur under the conditions of our main experiments. (Detailed information on the extra experiments is shown in the supplementary materials.)

\section{Discussion and implications}

The nonlinear dependence of $\mathrm{CO}_{2}$ emission on the baking soda concentration is similar to the trend in of Wohletz and Sheridan (1983). The reason why the maximum emission 


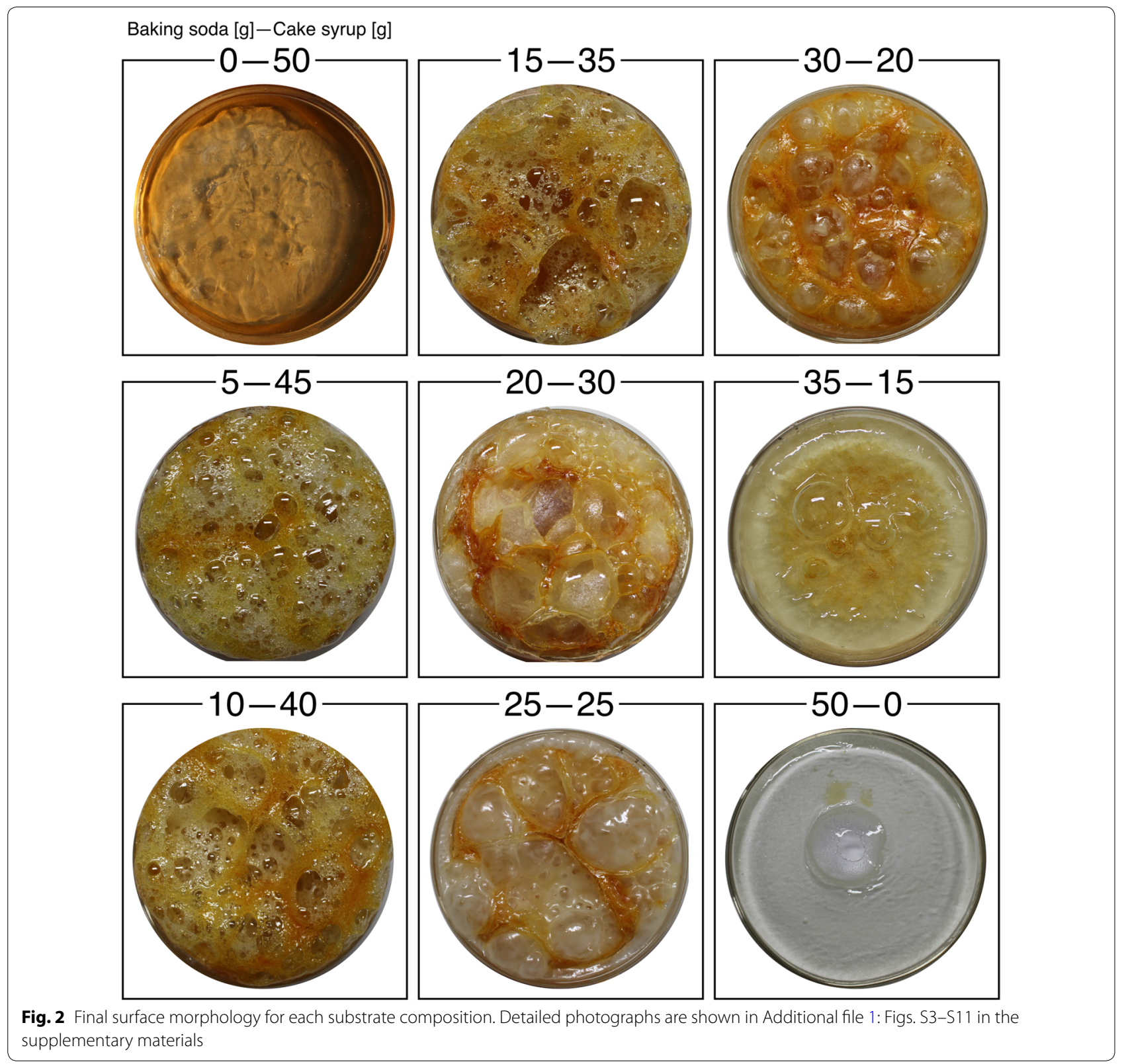

occurs at an intermediate value of the baking soda concentration is important for understanding the nonlinear relationship of explosion intensity in rootless eruptions. Based on the observation of RTI, we hypothesize that the heated syrup sinks into the substrate and warms the substrate, inducing a thermal decomposition reaction. In this hypothesis, two timescales are relevant; the cooling timescale, $\tau_{\text {cool }}$ and the sinking timescale, $\tau_{\text {sink }}$. The cooling timescale, $\tau_{\text {cool }}$ is given as follows:

$$
\tau_{\mathrm{cool}} \sim \frac{a^{2}}{\delta}
$$

where $a$ and $\delta$ are the thickness and thermal diffusivity of the substrate, respectively. Using $\delta \sim 10^{-7} \mathrm{~m}^{2} / \mathrm{s}$ (Kumagai et al. 2007, and references therein; we used the thermal diffusivity of syrup in place of that of the substrate), $\tau_{\text {cool }}$ is estimated as $\sim 10^{3} \mathrm{~s}$. The timescale can be shorter because the masses of the heated syrup and substrate were comparable in the experiments. The sinking timescale, $\tau_{\text {sink }}$, is estimated from the growth rate of RTI. The disturbance of height between two fluids, $w(t)$, increases exponentially as $w(t)=w_{0} e^{t / \tau}$ from the initial disturbance, $w_{0}$. In two-dimensional case, the wavelength, $\lambda$, and the growth rate, $\tau$, of the dominant disturbance of 


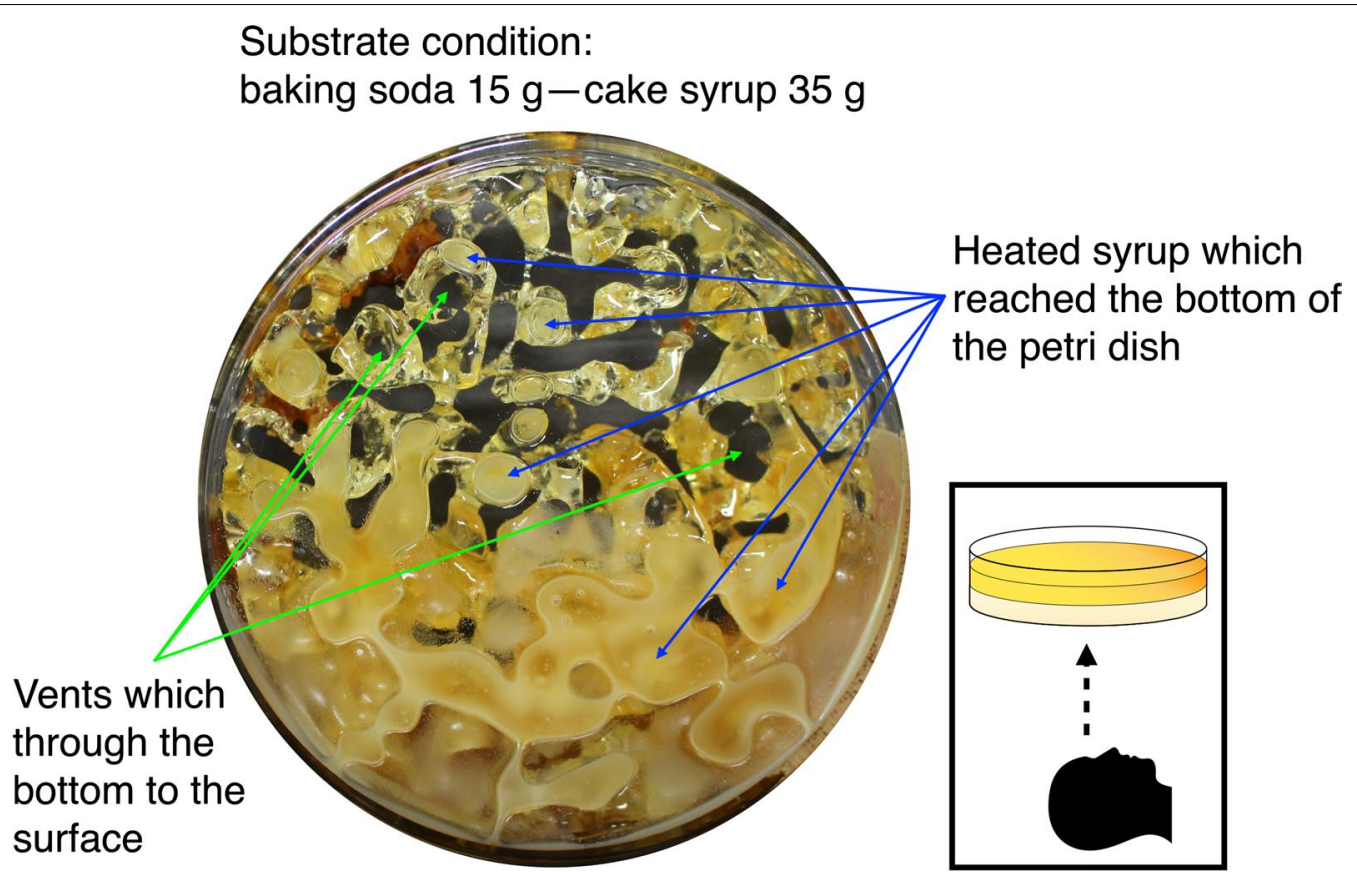

Fig. 3 Photograph of the petri dish after the experiment taken from below the dish. The substrate was removed. The heated syrup sank and sparsely reached the bottom of the petri dish. The substrate consisted of $15 \mathrm{~g}$ of baking soda and $35 \mathrm{~g}$ of cake syrup

RTI in fluids with the same thickness $(a)$ and the same viscosity $(\eta)$ are given by Turcotte and Schubert (2002):

$$
\lambda=2.568 a
$$

and

$$
\tau=\frac{13.04 \eta}{\left(\rho_{\text {syrup }}-\rho_{\text {substrate }}\right) g a} .
$$

Figure 4a shows the results of viscosity measurements of the substrate, which is a two-phase suspension mixture of cake syrup (liquid) and baking soda. The viscosity measurements were taken at constant shear rates $\left(1.3 \mathrm{~s}^{-1}\right.$ and $11 \mathrm{~s}^{-1}$ ) using a cone-plate-type rheometer (Bohlin $\mathrm{CVO}$, Malvern Instruments) at $25^{\circ} \mathrm{C}$. The viscosity gradually increases with the mass (i.e., concentration) of the baking soda for masses up to $15 \mathrm{~g}$ and then greatly increases for masses above $20 \mathrm{~g}$ (Fig. 4a). Although the growth rate of the disturbance by RTI $(\tau)$ varies with baking soda concentration, all growth rates are on the order of $1 \mathrm{~s}$ and sufficiently smaller than the cooling rate $\left(\tau_{\text {cool }}\right.$; Additional file 1: Table S2).

During the sinking of the heated syrup, the surrounding substrate is heated, inducing a thermal decomposition reaction. The amount of reaction products should scale with the volume of the heated region and the concentration of baking soda. The total amount of reaction products $(Q)$ is given as follows:

$$
Q=V \times C_{\text {soda }}
$$

where $V$ is the heated volume in the substrate and $C_{\text {soda }}$ is the concentration of baking soda (i.e., the mass of baking soda per unit volume in the substrate). Because we observed that the poured heated syrup sparsely reached the bottom of the petri dish, it is assumed that the volume of the substrate has been completely heated and can be used for the heated volume $V$ in this model. Figure $4 \mathrm{~b}$ compares the amount of $\mathrm{CO}_{2}$ emission estimated from the model with that measured in the experiments as a function of baking soda mass. Note that the amount of $\mathrm{CO}_{2}$ was calculated as $(Q / 84 / 2) \times 44$, where 84 and 44 are the molecular weights of baking soda and $\mathrm{CO}_{2}$, respectively, and 2 is the amount (mol) of decomposed $\mathrm{NaHCO}_{3}$. Both the estimated (Fig. 4b) and measured (Fig. 1b) amounts of $\mathrm{CO}_{2}$ emission have a peak at a baking soda mass of around $15 \mathrm{~g}$. When the density of the substrate is lower than that of the poured heated syrup (i.e., the mass of baking soda is less than $15 \mathrm{~g}$ ), RTI enhances the decomposition of the baking soda in the substrate. On the other hand, RTI barely occurs when the mass of baking soda is higher than $15 \mathrm{~g}$. The peak of $Q$ thus arises from the balance between the concentration of baking soda and the presence of RTI.

The key aspect for understanding the successive rootless eruptions in our analog experiments is the density difference between the upper layer and the 

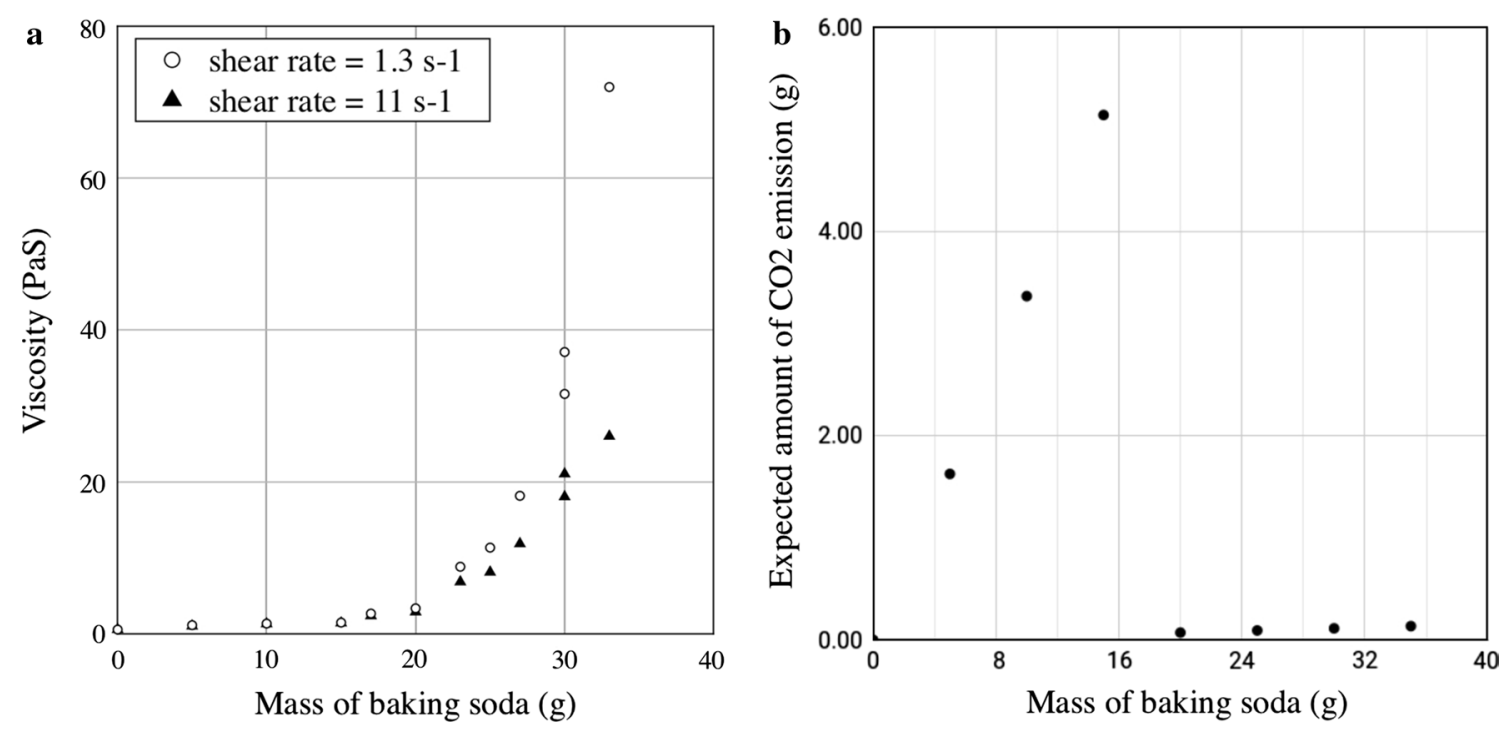

Fig. 4 a Rheological characteristics of substrates with various compositions. b Expected amount of $\mathrm{CO}_{2}$ emission calculated from viscosity (shear rate: $1.3 \mathrm{~s}^{-1}$ ) and concentration of baking soda. Details are given in the text

substrate that leads to RTI. Such a density difference, where the upper layer density is higher than the substrates density, is plausible in the case of lava flow over lacustrine sediments. The density of Younger Laxá lava in Iceland, which produced many rootless cones, is $1.49 \sim 2.21 \mathrm{~g} / \mathrm{cm}^{3}$ (Noguchi et al. 2016). The wet bulk density of lacustrine sediments under the lava flow has not been determined, but one example (in West Lake, Hangzhou, China; Yang et al. (2018)) is about $0.95 \sim 1.1 \mathrm{~g} / \mathrm{cm}^{3}$. Lava flow over lacustrine sediment could thus be gravitationally unstable. Adopting a lacustrine sediment viscosity of $10^{3} \mathrm{~Pa}$ s (Yang et al. 2018) and a lava flow thickness of $20 \mathrm{~m} \mathrm{(17} \mathrm{m} \mathrm{in}$ Höskuldsson et al. 2010), the characteristic time of RTI is order of $10^{-1} \mathrm{~s}$. The cooling rate of the lava flow is on the order of $10^{8} \mathrm{~s}$ based on a thermal diffusivity of $5 \times 10^{-7} \mathrm{~m}^{2} / \mathrm{s}$ (Gregg and Christle (2013), and references therein). Since the characteristic time of RTI is significantly shorter than the estimated cooling time, explosive interactions between lava and lacustrine sediments might be enhanced by the instability of the interfacial area due to the density variation, even in a natural system. To evaluate this further, detailed observation of natural rootless vents, which possibly stopped an explosion in a very early phase (Additional file 1: Fig. S14), could give hints.

In previous studies, the controlling factors of rootless eruptions have been regarded be (1) the mass ratio of water and magma, (2) the interfacial geometry between magma and substrates, (3) the injection rate of magma into substrates, and (4) the interpenetration degree between magma and water (Fagents and Thordarson 2007, and references therein). Our calculation model and experimental results are consistent with these factors.

The viscous behavior of the substrate correlates with observed bubble size in our experiment. The cases where small bubbles are dominant $(0-50,5-45,10-40$, and 15-35 substrates) mostly correspond to the low-viscosity phase of the substrate. A low viscosity of a substrate (i.e., a short $\tau_{\text {sink }}$ ) indicates a large contact area between the heated syrup and the substrate. $\mathrm{CO}_{2}$ gas is emitted successively at the interface and released as small bubbles. On the other hand, the cases where large bubbles appear (20-30, 25-25, 30-20, and 50-0 substrates) roughly correspond to the regime in which RTI could not occur. A lack of RTI indicates a small contact area between the heated syrup and substrate. In this case, the amount of $\mathrm{CO}_{2}$ gas emission is small. The highly viscous substrate also indicates shear thinning features (Fig. 4a). Under this condition, the first large bubble, which can form a stable vent, pulls surrounding bubbles. With further verification of the relationship between viscosity and bubble characteristics, including the spatial distribution, we can obtain useful information about the substrate conditions.

Based on consideration of the RTI, two parameters of the substrate, namely layer thickness and viscosity, are correlated with the characteristics of rootless cones, such as geomorphology and geospatial distribution. When lava flows onto thick substrates, it sinks for a longer time compared to that for thin substrates. This can be reflected by the ejected volume (i.e., the edifice size of 
rootless cones). Since the interaction efficiency is thought to correlate with the increasing rate of the interfacial area between lava and the substrate by RTI, the explosion intensity might be related to substrate viscosity. At a certain substrate viscosity, the interaction efficiency is maximized and the explosion intensity is strongest. In this condition, pyroclastic flows and ballistic ejections of pyroclasts are expected. At other substrate viscosities, the interaction efficiency is weaker, and spatters are expected as the products of the explosion. These differences between products may be reflected by the slope angle of the edifice (Noguchi et al. 2016). For a uniform grain size, the substrate viscosity can be correlated with water content. If the water content is high (i.e., lower substrate viscosity), since the wavelength of RTI is short, the geospatial density of rootless cones is expected to be dense. In the case of low water content (i.e., higher substrate viscosity), the geospatial density of rootless cones is expected to be sparse due to the longer wavelength of RTI. Therefore, substrate thickness and viscosity are expected to correlate with the edifice size, slope angle, and geospatial density of rootless cones. Although these correlations can also be affected by lava thickness and the competition of water with neighbor explosion points during eruptions (Hamilton et al. 2010b), we expect that with further verification using analog experiments and field observations, it may be possible to infer substrate properties from remote sensing geomorphology data (Additional files 2, 3, 4 and 5).

\section{Conclusion}

We demonstrated that the complication of the interface morphology between a molten hot ceiling and a loose wet substrate triggers and enhances rootless eruption in laboratory experiments using kitchen materials. In our experiments, the thermal decomposition reaction of baking soda was applied to create rootless eruptions. The maximum reaction efficiency was produced for a particular substrate composition (15 g of baking soda and $35 \mathrm{~g}$ of cake syrup). The nonlinear relationship between reaction efficiency and baking soda/poured heated syrup proportion resembles that found from a magma-water ratio diagram of Wohletz and Sheridan (1983) and subsequent studies. The rheological behavior of the poured heated syrup and the substrate indicates that the interaction surface between the poured heated syrup and the substrate affects reaction efficiency. Considering RTI in a natural setting, our study suggests that water availability and the rheological properties of the surface material affect the occurrence and stability of hydrovolcanic eruptions.

\section{Additional files}

Additional file 1. Supplementary material included figures and tables which appeared in the main text. Figure S1: The experimental system in this study. Figure S2: Package information of the products used in the experiment. Figure S3-S11: Detailed final surface morphology for each substrate composition. Figure $\mathbf{S 1 2}$ : The experimental system in an extra experiment for the Rayleigh-Taylor instability verification. Figure S13: Sinking of poured heated syrup (red) on the baking soda and cake syrup mixture substrate (green) in each substrate proportion. The proportion of baking soda and syrup is shown as, e.g., 15-35. Yellow dash lines show interfacial boundaries between the poured syrup and the substrate. Since this system is larger than that on the petri dish, we used three times of materials. The white bar indicates the length of $1 \mathrm{~cm}$. Figure S14: An example of hole on the lava (Kahuku basalt) which can be found near Ka Lae, Hawaii. The diameter and depth of the hole are $3.5 \mathrm{~m}$ and $1.4 \mathrm{~m}$, respectively. There is no ejecta around the hole. Inside the hole, blocks which are thought to be formed by the collapse of the rim exist. The wall surface has two layers: lower shingle roof-like lava and upper wellvesiculated lava.

Additional file 2. A fast-forward movie for an extra experiment to examine whether RTI occurs in the condition of the main experiment in the case of 45-105 of substrate condition which is same as 15-35 of the SC condition.

Additional file 3. A fast-forward movie for an extra experiment to examine whether RTI occurs in the condition of the main experiment in the case of $75-75$ of substrate condition which is same as $25-25$ of the SC condition

Additional file 4. A fast-forward movie for an extra experiment to examine whether RTI occurs in the condition of the main experiment in the case of $105-45$ of substrate condition which is same as $35-15$ of the SC condition.

Additional file 5. Mass loss change log, summary of experimental results, and shear rate measurement for the baking soda and cake syrup mixture substrate (Excel sheets).

\section{Authors' contributions}

All authors participated in the experiments, calculations, and discussions. RN designed the experiment protocol. KK measured the rheological properties. All authors read and approved the final manuscript.

\section{Author details}

${ }^{1}$ Volcanic Fluid Research Center, School of Science, Tokyo Institute of Technology, Tokyo, Japan. ${ }^{2}$ Present Address: Institute of Space and Astronautical Science, Japan Aerospace Exploration Agency, Tokyo, Japan. ${ }^{3}$ Central Research Institute of Electric Power Industry, Tokyo, Japan. ${ }^{4}$ Earthquake Research Institute, The University of Tokyo, Tokyo, Japan.

\section{Acknowledgements}

Discussions with the participants of a meeting called "Kitchen Earth Science," which was supported by the Earthquake Research Institute The University of Tokyo Joint Usage/Research Program, stimulated our research. We wish to thank Dr. Hiroki Ichikawa for his constructive comments and suggestions, which greatly improved the manuscript. We appreciate Dr. Ronaldo Ballouz and Dr. Lucie Riu for their generous effort in editing the English of this manuscript. We would also like to thank editor Kazutaka Mannen and two anonymous reviewers for their encouragements and constructive comments during the review process.

\section{Competing interests}

The authors declare that they have no competing interests. 


\section{Availability of data and materials}

Supplementary materials are available at: https://www.researchgate.net/publi cation/327051330_Supplementary_materials_for_Experimental_approach_ for_rootless_eruptions_using_kitchen_materials (https://doi.org/10.13140/ RG.2.2.15714.79048)

\section{Funding}

RN was supported by the Japan Society for the Promotion of Science (JSPS) Core-to-Core Program "International Network of Planetary Sciences" and JSPS $17 \mathrm{H} 06459$

\section{Publisher's Note}

Springer Nature remains neutral with regard to jurisdictional claims in published maps and institutional affiliations.

Received: 10 April 2018 Accepted: 10 December 2018 Published online: 27 December 2018

\section{References}

Andronico D, Cappelli L, Ciancitto F, Cioni R, Cristaldi A, Corsaro RA (2018) The 16 March 2017 phreatomagmatic explosion at Mt Etna, Italy. In: Corsaro RA., Di Giuseppe MG, Isaia R, Mormone A, Nave R (eds.) Millenia of stratification between human life and volcanoes: strategies for coexistenceCOV 10 abstracts volume, vol 43. Misc. INGV, pp 1-1300

Department of Land and Natural Resources (2018) 07/16/18 Ocean lava explosion injures 23 passengers on tour boat; state and federal investigation underway. In: Blog of DLNR. https://dlnr.hawaii.gov/blog/2018/07/16/ nr18-140/. Accessed 21 Sept 2018

Fagents SA, Thordarson T (2007) Rootless volcanic cones in Iceland and on Mars. In: Chapman M (ed) The geology of Mars. Cambridge University Press, Cambridge, pp 151-177

Fitch EP, Fagents SA, Thordarson T, Hamilton CW (2017) Fragmentation mechanisms associated with explosive lava-water interactions in a lacustrine environment. Bull Volcanol 79:12. https://doi.org/10.1007/ s00445-016-1087-3

Greeley R, Fagents SA (2001) Icelandic pseudocraters as analogs to some volcanic cones on Mars. J Geophys Res 106(E9):20527-20546. https://doi. org/10.1029/2000JE001378

Gregg TK, Christle KW (2013) Non-explosive lava-water interaction in Skaelingar, Iceland and the formation of subaerial lava pillars. J Volcanol Geotherm Res 264:36-48

Hamilton CW, Thordarson T, Fagents SA (2010a) Explosive lava-water interactions I: architecture and emplacement chronology of volcanic rootless cone groups in the 1783-1784 Laki lava flow, Iceland. Bull Volcanol 72:449-467. https://doi.org/10.1007/s00445-009-0330-6

Hamilton CW, Fagents SA, Thordarson T (2010b) Explosive lava-water interactions II: self-organization processes among volcanic rootless eruption sites in the 1783-1784 Laki lava flow, Iceland. Bull Volcanol 72:469-85. https://doi.org/10.1007/s00445-009-0331-5

Hamilton CW, Fitch EP, Fagents SA, Thordarson T (2017) Rootless tephra stratigraphy and emplacement processes. Bull Volcanol 79:11. https://doi. org/10.1007/s00445-016-1086-4

Höskuldsson Á, Dyhr C, Dolvik T (2010) Grænavatnsbruni og Laxárhraun yngra. Haustrá dstefna Jardfrædafélags Íslands, Ágrip erinda, pp. 41-44 (in Icelandic)
Kienle J, Kyle PR, Self S, Motyka RJ, Lorenz V (1980) Ukinrek Maars, Alaska, I. April 1977 eruption sequence, petrology and tectonic setting. J Volcanol Geotherm Res 7(1-2):11-37

Kumagai I, Davaille A, Kurita K (2007) On the fate of thermally buoyant mantle plumes at density interfaces. Earth Planet Sci Lett 254(1-2):180-193

Mattox TN, Mangan MT (1997) Littoral hydrovolcanic explosions: a case study of lava-seawater interaction at Kilauea Volcano. J Volcanol Geotherm Res 75:1-17

Noguchi R, Höskuldsson Á, Kurita K (2016) Detailed topographical, distributional, and material analyses of rootless cones in Myvatn, Iceland. J Volcanol Geotherm Res 318:89-102

Rayleigh L (1882) Investigations of the character of the equilibrium of an incompressible heavy fluid of variable density. Proc Lond Math Soc s1-14:170-177. https://doi.org/10.1112/plms/s1-14.1.170

Reynolds P, Brown RJ, Thordarson T, Llewellin EW, Fielding K (2015) Rootless cone eruption processes informed by dissected tephra deposits and conduits. Bull Volcanol 77(9):1-17

Sheridan MF, Wohletz KH (1983) Hydrovolcanism: basic considerations and review. J Volcanol Geotherm Res 17(1):1-29

Taylor Gl (1950) The instability of liquid surfaces when accelerated in a direction perpendicular to their planes. I. Proc R Soc Lond A 201(1065):192-196

Thorarinsson S (1953) The crater groups in Iceland. Bull Volcanologique 2:1-44

Thordarson T, Höskuldsson Á (2002) Iceland. Terra Publishing, Edinburgh, p 200

Thorkelsson B, Karlsdóttir S, Gylfason ÁG, Höskuldsson Á, Brandsdóttir B, Ilyinskaya E, Gudmundsson MT, Högnadóttir T (2012) The 2010 Eyjafjallajökull Eruption, Iceland. Report to ICAO-June 2012

Todesco M (2017) The leap in the dark: geological thoughts about an unpredictable planet. J Geophys Res 122:2780-2783. https://doi. org/10.1002/2017JB014274

Turcotte DL, Schubert G (2002) Geodynamics. Cambridge University Press, New York, p 456

U.S. Geological Survey (2018) Hawaiian volcano observatory status report: Kilauea volcano Monday, July 16, 2018, 9:31 AM HST (Monday, July 16, 2018, 19:31 UTC). In: Volcano hazards program. https://volcanoes.usgs. gov/vhp/archive_search.html. Accessed 20 Jul 2018

White JD, Valentine GA (2016) Magmatic versus phreatomagmatic fragmentation: absence of evidence is not evidence of absence. Geosphere 12(5):1478-1488

Wohletz KH (2002) Water/magma interaction: some theory and experiments on peperite formation. J Volcanol Geotherm Res 114:19-35

Wohletz KH, Sheridan MF (1983) Hydrovolcanic explosions; II, evolution of basaltic tuff rings and tuff cones. Am J Sci 283(5):385-413

Wood CA (1979) Monogenetic volcanoes of the terrestrial planets. In: Proceedings of lunar and planetnetary science conference, 10th, pp 2815-2840

Yamamoto T, Soya T, Suto S, Uto K, Takada A, Sakaguchi K, Ono K (1991) The 1989 submarine eruption off eastern Izu Peninsula, Japan: ejecta and eruption mechanisms. Bull Volcanol 53(4):301-308

Yang W, Yu M, Yu G (2018) Stratification and rheological properties of nearbed cohesive sediments in West Lake, Hangzhou, China. J Coastal Res 34(1):185-192

Zimanowski B, Büttner R, Lorenz V (1997) Premixing of magma and water in MFCl experiments. Bull Volcanol 58:491. https://doi.org/10.1007/s0044 50050157 